\title{
Histomorphological study of chorionic villi in products of conception following first trimester abortions
}

\author{
Shilpa MD', Supreetha MS ${ }^{2}$, Varshashree ${ }^{3}$ \\ ${ }^{1}$ Dr. Shilpa, MD, Assistant Professor, ${ }^{2}$ Dr. Supreetha, MS, Assistant Professor, ${ }^{3}$ Dr. Varshashree, Post graduate, all \\ authors are affiliated with Department of Pathology, Sri Devaraj Urs Medical College, Tamaka, Kolar, Karnataka, India.
}

Corresponding Author: Dr. Shilpa, MD, Assistant Professor, Department of Pathology, Sri Devaraj Urs Medical College, Tamaka, Kolar, Karnataka, India. Email id: mdshilpa@gmail.com

\begin{abstract}
Background: The common problem which occurs in first trimester of pregnancy is miscarriage. Retained products of conception are commonly received specimen for histopathological examination. Apart from confirmation of pregnancy, a careful examination can provide some additional information about the cause or the conditions associated with abortion. Aim: 1. To study various histopathological changes occurring in chorionic villi in first trimester spontaneous abortions and to know the pathogenesis of abortions. Materials and methods: This was a cross sectional retrospective study carried out for over a period of 3 years from January 2015 to January 2018. A total of 235biopsies were obtained from patient with the diagnosis of the first trimester spontaneous abortions were included in this study. Results: In our study most common age group of the abortion was between 21-30 years (63\%). Incomplete abortion was the commonest type of abortion (47.7\%). Many dysmorphic features were observed in this study like hydropic change (67\%), stromal fibrosis $(62 \%)$, villi with reduced blood vessels $(52.7 \%)$ and perivillous fibrin deposition. Other features seen were haemorrhage, fibrinoid degeneration, Aria Stella reaction and calcification. Reduced blood vessels in the villi had statistically significant association with stromal fibrosis and hydropic change which was $<0.05$. Conclusion: Cases with dysmorphic features as seen in the present study may be associated with certain chromosomal abnormalities. Such cases can not only be filtered for cytogenetic work up, but these features can also aid in counselling and planning of future pregnancies. Thus histopathological examination of abortus material is highly recommended.
\end{abstract}

Keywords: First trimester abortion, Chorionic villi, fibrosis, Vascularity

\section{Introduction}

The commonest complication of pregnancy is abortion. Its incidence is around $15 \%$ [1]. The higher frequency of abortions in first trimester is mainly due to genetic aberrations and the exact etiology is still unknown [2]. The pathology of spontaneous abortions is therefore an important aspect necessary for understanding the etiology and pathogenesis of the abortions. Foetal and placental development occurs hand in hand.

The foetal developmental abnormalities will be reflected with the changes observed in the foetal part of placenta and it is recognized by the uterus as abnormal and thus the uterus expels such products giving rise to spontaneous abortions [3]. There may be local, systemic and combined means of pathology for abnormal placental development and induction of abortion [4]. Thus, histopathological examination of products of

Manuscript received: $30^{\text {th }}$ October 2018

Reviewed: $8^{\text {th }}$ November 2018

Author Corrected: $16^{\text {th }}$ November 2018

Accepted for Publication: $20^{\text {th }}$ November 2018 conception is a routine test for management of patients with early pregnancy failure. The main reasons for doing histopathological examination for products of conception are to prove the presence of an intrauterine gestation and to understand the etiology and pathogenesis of abortions. But still there is lot of debate on it whether is it necessary to send for routine histopathological examination or not. Hence the aim of the study was to see various histopathological changes occurring in chorionic villi in first trimester spontaneous abortions and to know the pathogenesis of abortions.

\section{Materials and Methods}

It was a laboratory exploratory study carried out in department of pathology, R L Jalappa Hospital attached to Sri Devaraj Urs Medical College. Institutional ethical clearance was taken from ethical committee. The study included all the specimens of products of conception 


\section{Original Research Article}

after spontaneous abortion submitted for histopathological examination for over a period of 3 years from January 2015 to January 2018 were considered. Relevant clinical history was retrieved from requisition forms.

All the specimens received in formalin were routinely fixed and stained with Hematoxylin and eosin. These slides were examined for various histological lesions in the chorionic villi. Special stains were used wherever necessary.

The following histological parameters were studied which suggests villous maldevelopment or degeneration $[5,6]$.
1) Villous size
2) Villous vasculature
3) Trophoblastic proliferation

4) Ghost villi

5) Stromal fibrosis

6) Aria Stella reaction

7) Decidualised tissue

8) Perivillous fibrin deposition

9) Hydropic degeneration

10) Hofbauer macrophages

Exclusion Criteria: Curetted samples of spontaneous first trimester abortions and with associated risk factors like diabetes, hypertension, and infections were excluded.

Statistical Analysis was done by using Microsoft excel and by using SPSS 22 software analysis and $p$ value $<$ 0.05 was considered significant.

\section{Results}

A total of 235 cases were retrieved of which 15 cases were excluded who had undergone medical termination of pregnancy voluntarily. The patient age ranged from 18 to 40 years. Most of the cases belonged to the age group 21-30 years which was statistically significant [Table 1].

Table-1: Age distribution.

\begin{tabular}{|c|c|c|}
\hline Age & N\% & p-value \\
\hline$\leq 20$ & $54(24.5 \%)$ & \multirow{2}{*}{$<0.05$} \\
\hline $21-30$ & $140(63 \%)$ & \\
\hline $31-40$ & $26(11.8 \%)$ & \\
\hline
\end{tabular}

The types of abortion were classified as shown in the [Table 2]. The most common type of abortion seen in this study was incomplete abortion which was seen in 105 patients which formed the highest percentage while inevitable abortion formed the lowest percentage.

Table-2: Types of abortion.

\begin{tabular}{|c|c|c|}
\hline Type of abortion & Number & Percentage \\
\hline Incomplete & 105 & $47.7 \%$ \\
\hline Missed & 70 & $31.8 \%$ \\
\hline Complete & 36 & $16.3 \%$ \\
\hline Inevitable & 9 & $0.04 \%$ \\
\hline Total & $\mathbf{2 2 0}$ & $\mathbf{1 0 0} \%$ \\
\hline
\end{tabular}

The present study on histomorphological analysis showed that the most common size of the villi was the intermediate size which was seen in 144 cases (65.5\%)[Fig 1] followed by large and small villi [Table 3]. Among villous vascularity grade 3 was the commonest i.e., a plastic or hypoplastic villi which was seen in 116 cases (57.9\%).

Other common morphological findings which were seen are hydropic change [Fig 2] followed by stromal fibrosis [Fig 3\&4], fibrinoid degeneration, per villousfibrin, intervillous haemorrhage and Hofbauermacrophages [Table 4]. Molar pregnancies were seen in 15 cases. 


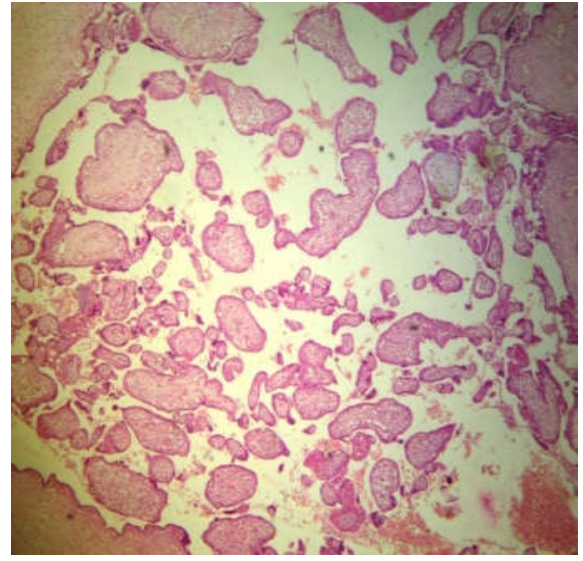

Fig 1: Microphotograph of chorionic villi with small and intermediate sized villi $H \& E$ stain (100X)

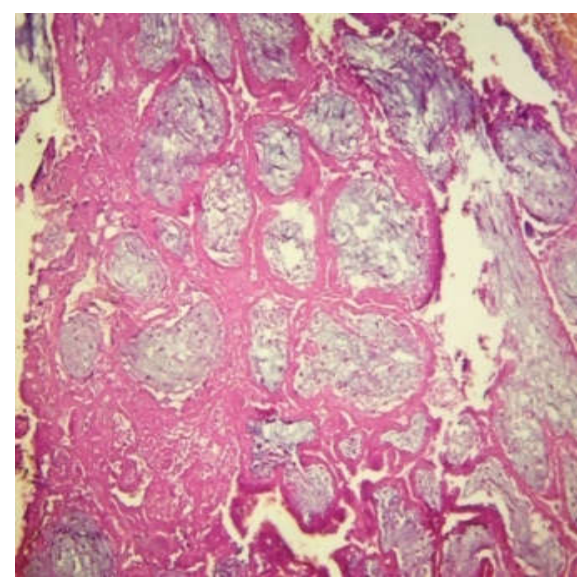

Fig 3: Microphotograph of chorionic villi with stromal fibrosis H\&E stain (100X)

Table-3: Histomorphology of chorionic villi

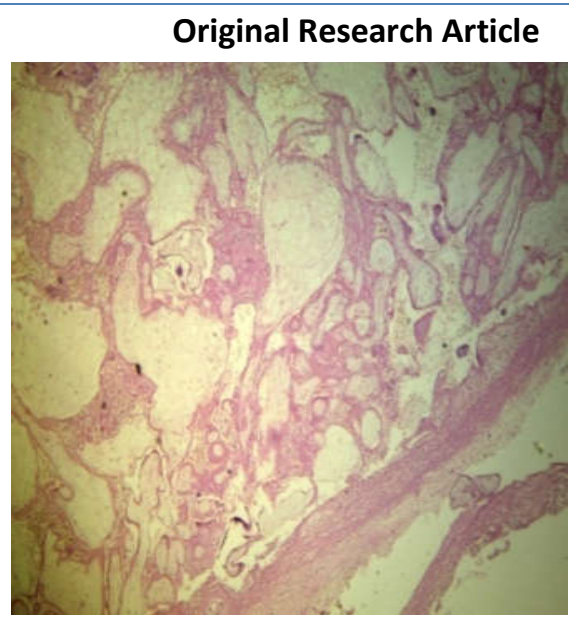

Fig 2: Microphotograph of chorionic villi with hydropic degeneration H\&E stain (100X)

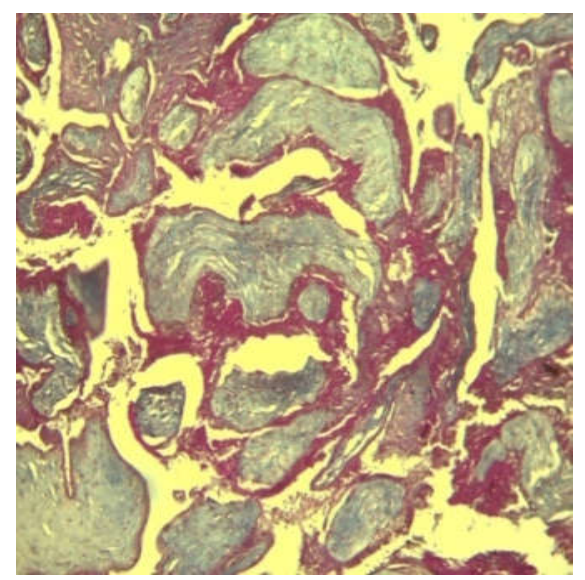

Fig-4: Microphotograph of Chorionic villiMasson Trichrome stain highlighting the fibrosis (400X)

\begin{tabular}{|c|c|c|}
\hline Villous Size & Number & Percent \\
\hline Small & 37 & 65.5 \\
\hline Intermediate & 144 & 17.7 \\
\hline Large & 39 & 100 \\
\hline Total & 220 & 18.6 \\
\hline Villous Vascularity & & 28.6 \\
\hline Grade 1 & 41 & 52.7 \\
\hline Grade 2 & 63 & 100 \\
\hline Grade 3 & 116 & \\
\hline Total & 220 & \\
\hline
\end{tabular}




\section{Original Research Article}

Table-4: Other morphological findings.

\begin{tabular}{|c|c|c|}
\hline Histological findings & Number & Percentage \\
\hline Hydropic change & 149 & 67 \\
\hline Stromal fibrosis & 139 & 63.1 \\
\hline Fibrinoid degeneration & 105 & 47.7 \\
\hline Hofbauer cells & 102 & 46.3 \\
\hline Decidual inflammation & 74 & 33.6 \\
\hline Haemorrhage & 68 & 30.9 \\
\hline Perivillous fibrin & 68 & 30.9 \\
\hline Hyalinized villi & 30 & 13.6 \\
\hline Molar changes & 15 & 0.06 \\
\hline Aria Stella reaction & 12 & 0.05 \\
\hline Calcification & 10 & 0.04 \\
\hline
\end{tabular}

Table-5: Association between villous vasculature and stromal fibrosis

\begin{tabular}{|c|c|c|c|c|}
\hline Villous vasculature & \multicolumn{3}{|c|}{ Stromal fibrosis } & P value \\
\hline & Present & absent & Total & \multirow{2}{*}{$\mathrm{p}<0.05$} \\
\hline Grade I & 24 & 17 & 41 & 63 \\
\hline Grade II & 35 & 28 & 116 & \\
\hline Grade III & 85 & 31 & $\mathbf{2 2 0}$ & \\
\hline Total & $\mathbf{1 4 4}$ & $\mathbf{7 6}$ & & \\
\hline
\end{tabular}

Table-6: Association between villous vasculature and hydropic degeneration

\begin{tabular}{|c|c|c|c|c|}
\hline Villous vasculature & \multicolumn{3}{|c|}{ Hydropic degeneration } & P value \\
\hline & Present & Absent & Total & \multirow{2}{*}{$\mathrm{P}<0.05$} \\
\hline Grade I & 23 & 18 & 41 \\
\hline Grade II & 30 & 33 & 63 \\
\hline Grade III & 96 & 20 & 116 \\
\hline Total & $\mathbf{1 4 9}$ & $\mathbf{7 1}$ & $\mathbf{2 2 0}$ & \\
\hline
\end{tabular}

Aria- Stellareaction was seen in 12 cases. Decidual reaction i.e., Inflammatory reaction consisting of mixture of neutrophils, lymphocytes and plasma cells in the decidua were seen in 74 cases. Ghost villi or hyalinized villi were seen in 30 cases and calcification was seen in 10 cases. Statistical analysis was done and it was seen that there was statistical significance between the villous vasculature and stromal fibrosis [Table 5] i.e., the villi having grade III vascularity showed increased stromal fibrosis. This significance was also seen with villous vasculature and hydropic change i.e., villi showing grade III vascularity had increased hydropic change [Table 6]. Stromal fibrosis was highlighted by special stain Masson's trichrome stain.

\section{Discussion}

The functional unit of placenta is chorionic villi which develops from chorion and has got a maximum contact with maternal blood and provides nutrition and oxygen to the foetus similar to lung acinus and also serves as an excretory unit like renal glomerulus [1]. WHO (World Health Organization) defines spontaneous miscarriage as expulsion or extraction of an embryo or foetus weighing 500 grams or less from its mother which occurs before the foetus has reached a viable gestational age $[8,9]$.
The products of conception which are passed during spontaneous abortion should be sent for histopathological examination and it should become a routine practice since it has got a great value not only in confirmation of pregnancy but also ruling out molar, ectopic pregnancies and most important is gestational trophoblastic diseases which needs further follow up [5]. The chorionic villi is lined by inner layer of cytotrophoblast and outer layer of syncytiotrophoblast. During early stages of pregnancy most of the pathological lesions occur $[8,10]$. Many authors have 


\section{Original Research Article}

concluded that histopathological examination of products of conceptions helps to diagnose important pathologies more effectively when compared to clinical examination so that mortality can be reduced [11,12]. In this study we have tried to evaluate the histological findings in the chorionic villi of first trimester spontaneous abortions. In the present study, the majority of women belonged to age group between 2130 years which was statistically significant $p<0.05$ with minimum age of 18 years and maximum age of 40 years. Similar findings were also noted in a study done by Makaju et al[8]. In our study incomplete abortion was the most common type which was seen in 105 cases. This was in accordance to the study done on 100 cases [13]. The least common was inevitable abortion.

The most important morphological villous criteria used to investigate early pregnancy loss were regularity of the villous size, villousvas culture, stromal fibrosis and perivillous fibrin deposition. Small sized villi with increased syncytial knots, decreased vascularity and irregular contour are features of trisomies [13]. In the present study small sized villi were seen in $16.5 \%$ of the cases. For confirmation karyotyping was not done in this study and majority of the villi were of intermediate size. Other histological findings which were seen on light microscopy are hydropic villi, poorly vascularized villi, villous haemorrhages, perivillous and intravillous fibrin deposition, Hofbauer macrophages, ghost villi and calcification. Out of these most important finding was stromal fibrosis and hydropic change which were statistically significant with the villous vascularity.

First trimester chorionic villi show 8-10 vessels per villous. In our study majority had decreased vessels and it was the significant finding and statistical significance was found between villous vascularity and stromal fibrosis. Avascular or hypovascular villi means poor blood supply to the foetus and will result in foetal retardation $[7,13]$.

Stromal fibrosis was another significant finding which was observed. It is the final common pathway for all form of diseases that progress towards end stage failure. This is caused by the activation of the basement membrane material and extracellular matrix molecules like collagen I, II, III, fibronectin IV and proteoglycans by the resident cells of the chorionic villi. This is a feature associated with preeclampsia and diabetic pregnancies. It is also a finding seen after intrauterine foetal death regression $[13,14]$. This fibrosis can lead to decreased blood vessels in the villi. Hydropic degeneration is a tissue reaction to the pathological insult. In this study there was statistical significance between villous vascularity and hydropic change. This explains that initially there is stromal edema and later the avascular villi become edematous and causes blighted ova [15]. Extreme hydropic change is a characteristic finding in molar pregnancy [1]. In our study it was seen in 12 cases. Perivillous and intervillous haemorrhage usually occurs due break of numerous barriers from the foetal circulation into the maternal intervillous space $[15,16]$. These findings were also seen in our study. Haemorrhages seeps through adjacent decidua and forms a membrane like sheet around the chorionic villi. At few places it breaks into the villous stroma and forms fibrin deposition leading to fibrinoid degeneration [7]. Perivillous and intervillous fibrin formed from these haemorrhages. Increased peri villous fibrin causes entrapment of the villi which become infarcted due decreased blood supply [13, 14].

Hofbauer cells also called as placental macrophages, which are found to be derived from foetal hematopoietic cells in liver and yolk sac. They help in biologic events of placenta like fluid balance, immunologic and inflammatory processes. It is said that increase in hofbauer cells in can cause immunologic or inflammatory insult leading to missed abortion [17]. In our study it was seen in 55 cases. Decrease in number of Hofbauercells along with avascularity of the chorionic villi can cause hypoxia which leads to blighted ovum. Aria Stella reaction and decidual inflammation are the other features which were observed. Decidual inflammation is defined as diffuse lymphocytic infiltrate of the basal plate or any infiltrate in the decidua basalis which includes plasma cells [15].

Another feature observed was calcification. The cause for calcification is the ischemic hypoxia degeneration and necrosis followed by calcium deposition in the necrotic area. In this study it was seen in only few cases.

\section{Conclusion}

The microscopic analysis of villous features helps in confirmation of pregnancy and also identifies the cause for first trimester abortions which can be either small size of the villi, stromalfibrosis, and decreased vascularity of the villi. This helps further in cytogenetic evaluation of these cases which can be done and it predicts the future of subsequent pregnancies so that proper intervention and counselling can be given. It also provides a clue of unsuspected molar pregnancies and associated clinical conditions like diabetes and preeclampsia so that proper treatment can be given. Hence careful microscopic examination of the products of conception after spontaneous abortion can be a useful guide to identify many important lesions and also 


\section{Original Research Article}

provides useful information so that proper treatment can be provided further.

Findings: Nil; Conflict of Interest: None initiated Permission from IRB: Yes

\section{References}

1. Crum, Christopher P. The Female Genital Tract. In: Ramzi S. Cotran. Vinay Kumar, and Tucker Collins: Robbins Pathologic Basisof Disease, 8th ed. Philadelphia: W.B. Saunders, 2007; 1079-80.

2. Kalousek DK, Law AE. Pathology of spontaneous abortion In Dimmick JE, Kaulousek DK: Developmental Pathology of the embryo and fetus: Philadelphia: JBLippincot, 1992: 62-68.

3. Lesely Regan, Katy Clifford. Sporadic \& Recurrent Miscarriage. In: Geoffrey Chamberlain, Philip J Steer. Turnbull's Obstetrics. 3rd ed. Philadelphia: Churchill Livingstone 2001; 117-125.

4. Novak R, Agamanolis D, Dasu S, et al. Histologic analysis of placental tissue in first trimester abortions. Pediatr Pathol. 1988;8(5):477- 482.

5. Alsibiani SA, Value of Histopathologic Examination of Uterine Products after First-Trimester Miscarriage. BioMed Research International, 2014; 1:1-5

6. Jauniaux E, Burton GJ. Pathophysiology of histological changes in early pregnancy loss. Placenta. 2005 Feb-Mar; 26(2-3): 114-123. DOI:10.1016/j. placenta. 2004.05.011

7.HaqueAU,Siddique S, Jafari MM, Hussain I, Siddiqui S. Pathology of chorionic villi in spontaneous abortions. International Journal of Pathology 2004; 2 (5): 5-9.

8. Makaju R, Shrestha S, Sharma S, et al. Histopathological Changes in the Chorionic Villi and Endometrial Decidual Tissues in the Product of Conception of Spontaneous Abortion Cases. Kathmandu Univ Med J (KUMJ). 2015 Oct-Dec;13 (52) : 357-360.
9. F. Garycunningham KJL, Steve L Bloom, John C Hanth, Dwight J Rouse, Catherine Y Spong, editor. Williams Obstetrics. 23rd ed. United States of America: McGraw Hill Medical; 2010.

10. Vijay V Joshi. Handbook of Placental Pathology. New York; Igaku-Shoin: 1994.

11. Rashid PA. The role of histopathological examination of the products of conception following first trimester miscarriage in Ebril Maternity Hospital. Zanco J. Med. Sci; 21(3): 1938-1942.

12. Fram KM. Histological analysis of the products of conception following first trimester abortion at Jordan University Hospital. Eur J Obstet Gynecol Reprod Biol. 2002 Nov 15;105(2):147-149.

13. Shetty A, Narasimha A. histopathological Study of Villous Morphology In Spontaneous First Trimester Abortions. Annals Journal of Pathology and Laboratory Medicine 2016; 3: 451-457.

14. Chauhan K, Chaudary M, Garg M, Auplish R, Sangwan K, Mahajan N. Placental Pathology in Spontaneous Abortions: A study with review of literature. Annals Journal of Pathology and Laboratory Medicine 2016; 3(2): 73-80.

15. Folescu R, Motoc AG, Zamfir CL, Ilie AC. Anatomical and histological considerations of placenta vascular diseases with implications in forensic medicine. Rom J Morphol Embryol. 2014;55(2 Suppl): 579-583.

16. Habek D. Multiple intraplacental hematomas-Kline's hemorrhage. Acta Clin Croat. 2011 Sep;50(3): 423-5.

17. Karakaya YA, Ozer E. The role of Hofbauer cells on the pathogenesis of early pregnancy loss. Placenta. 2013 Dec; 34(12):1211-1215. doi: 10.1016/j. placenta. 2013.10.010. Epub 2013 Oct 27.

\section{How to cite this article?}

Shilpa, MD, Supreetha, MS, Varshashree. Histomorphological study of chorionic villi in products of conception following first trimester abortions. Trop J Path Micro 2018;4(7):499-504.doi:10.17511/jopm.2018.i07.04. 